\title{
Supramolecular Architecture of 7-Azaindole Based Ag(I) Complexes
}

\author{
Eunji Lee, Narae Jung, Haklin Kim, Ki-Min Park, ${ }^{\dagger, *}$ Jinho Kim, and Youngjin Kang ${ }^{*}$ \\ Division of Science Education \& Department of Chemistry, Kangwon National University, Chuncheon 200-701, Korea \\ *E-mail: kangy@kangwon.ac.kr \\ ${ }^{\dagger}$ Department of Chemistry (WCU) and Research Institute of Natural Science, Gyeongsang National University, \\ Jinju 660-701, Korea.*E-mail: kmpark@gnu.ac.kr \\ Received July 12, 2010, Accepted August 18, 2010
}

Key Words: Coordination chemistry, Ag(I) ion, Metallosupramolecule, Photophysical property, Crystal structure

Nitrogen heterocycles are extensively used as ligands in coordination chemistry, and the search of new ligands for novel self-assembled metallosupramolecular architectures remains of great interest. ${ }^{1}$ Among the nitrogen heterocycles, especially, nitrogen-donor chelated organic ligands based on 7-azaindole have recently attracted considerable interest because of their applications in organic light-emitting diodes (OLEDs), coordination chemistry of main groups and/or transition metals, and their functionalities of potential building blocks for supramolecular nanoengineering. ${ }^{2}$ Interestingly, the coordination modes to group 10 metal ions vary according to ligand used and the position of 7-azaindole unit in benzene ring. ${ }^{3}$ For example, the 1,3-bis(7-azaindolyl)benzene ligand has been found to bind to $\mathrm{Pd}(\mathrm{II})$ or $\mathrm{Pt}(\mathrm{II})$ centers as a tridentate NCN-type through cyclometallation (type 1). ${ }^{4}$ In contrast, the 1,2-bis(7-azaindolyl) benzene ligand usually acts as a bidentate ligand through the two 7-azaindolyl groups (type 2), ${ }^{5}$ as shown in Chart 1.

As we reported previously, 7-azaindole based transition metal complexes have been found to exhibit unusual structural features and chemical reactivity. ${ }^{6}$

Continuing our research on new luminescent heterocyclic molecules, ${ }^{7}$ we decided to explore the metal-coordination ca-

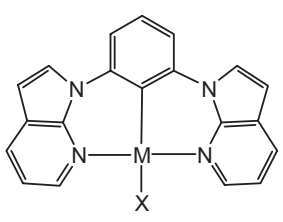

(a)

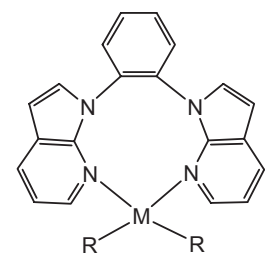

(b)
Chart 1. (a) type 1, (b) type 2; $M=$ Group $10, X=$ halide, $R=$ alkyl pabilities of the 1,4-bis(7-azaindoly)benzene. Silver(I) ion can be employed as an angular directional unit, as it is known to exhibit a linear or T-shaped coordination mode. ${ }^{8}$

We report here a new synthesis of this ligand and its X-ray structure and photophysical property. To our knowledge, only one study on the $\operatorname{Ag}(\mathrm{I})$ complexes using 2,2-dipyridylamine as a ligand can be found, ${ }^{9}$ and moreover no literature has mentioned metal complexes of 1,4-bis(7-azaindoly)benzene.

The ligand (L), 1,4-bis(7-azaindolyl)benzene, was obtained by the Ullmann condensation ${ }^{10}$ reaction of 7-azaindole with 0.5 equivalent of 1,4-dibromobenzene at $210-220^{\circ} \mathrm{C}$, in the presence of $\mathrm{CuSO}_{4}$ and $\mathrm{K}_{2} \mathrm{CO}_{3}$ (as a catalyst and a bromide scavenger, respectively) (Scheme 1). The ligand is soluble in most organic solvents, and is stable in both the solid and solution states. It was fully characterized by ${ }^{1} \mathrm{H}-\mathrm{NMR},{ }^{13} \mathrm{C}-\mathrm{NMR}$, and elemental analysis. The ligand reacts readily with $\mathrm{AgX}(\mathrm{X}=$ $\mathrm{CF}_{3} \mathrm{COO}, \mathrm{NO}_{3}$ ) in THF solution to afford complexes $\mathbf{1}$ and $\mathbf{2}$, in good yields. Reacting the ligand with $\mathrm{AgX}$, we obtained white solids, which displayed blue luminescence at ambient temperature.

The X-ray analyses revealed that both single crystals are unique zigzag type 1-D coordination polymers with repeating units, $\left[\mathrm{Ag}(\mathbf{L})\left(\mathrm{CF}_{3} \mathrm{CO}_{2}\right)\right]\left(\mathrm{H}_{2} \mathrm{O}\right)_{2}$ for $\mathbf{1}$ and $\left[\mathrm{Ag}(\mathbf{L})\left(\mathrm{H}_{2} \mathrm{O}\right)\right]\left(\mathrm{NO}_{3}\right)$ for $\mathbf{2}$. Their crystal structures are shown in Figure 1. Selected bond lengths and angles are listed in Table 2. For coordination polymer $\mathbf{1}$, the ligand $\mathbf{L}$ has a crystallographically imposed inversion center. Therefore the asymmetric unit of 1 consists of two crystallographically independent one half of $\mathbf{L}$, one $\mathrm{Ag}$ atom, one $\mathrm{CF}_{3} \mathrm{CO}_{2}^{-}$and two water molecules. As shown in Figure 1a, each $\mathrm{Ag}(\mathrm{I})$ atom links two 7-azaindolyl $\mathrm{N}$ atoms from two different ligands [Ag1-N1 2.241(3) $\AA$, Ag1-N3 2.237(3) $\AA$ ] and is also coordinated to one $\mathrm{O}$ atom from trifluoroacetate bound in a monodentate manner with a bond length [Ag1-O1 2.512(3) $\AA$ ].

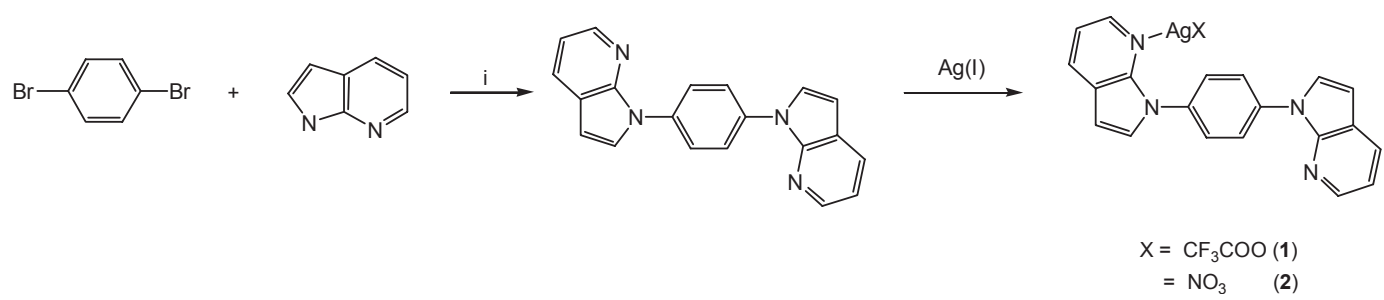

Scheme 1. Synthetic routes; i) 7-azaindole (2 eq), $\mathrm{K}_{2} \mathrm{CO}_{3}(0.05 \mathrm{eq}), \mathrm{CuSO}_{4} \cdot 5 \mathrm{H}_{2} \mathrm{O}(0.05 \mathrm{eq}), 200{ }^{\circ} \mathrm{C}, 12 \mathrm{~h}$ 
Table 1. Crystallographic data and structure refinement for $\mathbf{1}$ and $\mathbf{2}$

\begin{tabular}{lll}
\hline Compound & \multicolumn{1}{c}{$\mathbf{1}$} & \multicolumn{1}{c}{$\mathbf{2}$} \\
\hline Chemical formula & $\mathrm{C}_{22} \mathrm{H}_{18} \mathrm{AgF}_{3} \mathrm{~N}_{4} \mathrm{O}_{4}$ & $\mathrm{C}_{20} \mathrm{H}_{16} \mathrm{AgN}_{5} \mathrm{O}_{4}$ \\
Formula weight & 567.27 & 498.25 \\
$T(\mathrm{~K})$ & $173(2)$ & $173(2)$ \\
Crystal system & Triclinic & Orthorhombic \\
Space group & $P-1$ & $P b c a$ \\
$a(\AA)$ & $9.0737(4)$ & $13.4242(4)$ \\
$b(\AA)$ & $10.8618(4)$ & $8.3248(3)$ \\
$c(\AA)$ & $12.0792(5)$ & $32.7107(10)$ \\
$\alpha\left({ }^{\circ}\right)$ & $69.4510(10)$ & 90 \\
$\beta\left({ }^{\circ}\right)$ & $88.6850(10)$ & 90 \\
$\gamma\left({ }^{\circ}\right)$ & $77.1670(10)$ & 90 \\
$V\left(\AA^{3}\right)$ & $1084.92(8)$ & $3655.5(2)$ \\
$Z$ & 2 & 8 \\
Absorption coefficient $\left(\mathrm{mm}^{-1}\right)$ & 0.993 & 1.144 \\
$F(000)$ & 568 & 2000 \\
Crystal size $\left(\mathrm{mm}^{3}\right)$ & $0.30 \times 0.10 \times 0.10$ & $0.35 \times 0.20 \times 0.20$ \\
$\theta$ range $\left({ }^{\circ}\right)$ & 1.80 to 26.50 & 1.25 to 26.00 \\
Reflections collected/Unique & $6514 / 4431$ & $19564 / 3590$ \\
Absorption correction & None & None \\
No. variables & 326 & 271 \\
Refl./para. ratio & 13.59 & 13.24 \\
Goodness-of-fit on $F^{2}$ & 1.050 & 1.070 \\
Final $R_{1}, w R_{2}[I>2 \sigma(I)]$ & $R_{1}=0.0396, w R_{2}=0.0964$ & $R_{1}=0.0560, w R_{2}=0.1015$ \\
$R($ all data) & $R_{1}=0.0444, w R_{2}=0.1002$ & $R_{1}=0.0635, w R_{2}=0.1048$ \\
& & \\
& &
\end{tabular}

Table 2. Selected bond lengths $(\AA)$ and bond angles $\left(^{\circ}\right)$ for $\mathbf{1}$ and $\mathbf{2}$

\begin{tabular}{llll}
\hline Complex 1 & & & \\
Ag1-N1 & $2.241(3)$ & Ag1-N3 & $2.237(3)$ \\
Ag1-O1 & $2.512(3)$ & & \\
N1-Ag1-N3 & $173.87(11)$ & N1-Ag1-O1 & $96.01(11)$ \\
N3-Ag1-O1 & $89.78(11)$ & & \\
Complex 2 & & & \\
Ag1-N1 & $2.268(4)$ & Ag1-N4 & \\
Ag1-O1W & $2.692(4)$ & & $2.243(4)$ \\
N1-Ag1-N4 & $169.20(14)$ & N1-Ag1-O1W & $94.51(13)$ \\
N4-Ag1-O1W & $94.39(13)$ & & \\
\hline
\end{tabular}

Symmetry code: i) $-x+1 / 2, y-1 / 2, z$

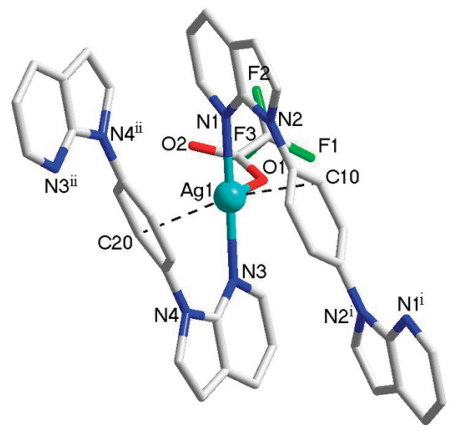

(a)

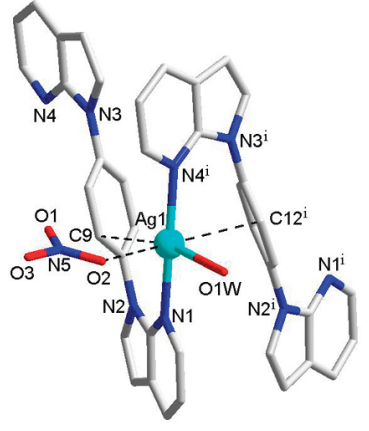

(b)
Figure 1. Crystal structures of (a) $\mathbf{1},\left\{\left[\mathrm{Ag}(\mathbf{L})\left(\mathrm{CF}_{3} \mathrm{CO}_{2}\right)\right]\left(\mathrm{H}_{2} \mathrm{O}\right)_{2}\right\}_{n}[\mathrm{sym}-$ metry codes: i) $2-x,-y,-z$; ii) $1-x,-y,-z]$ and (b) $2,\left\{\left[\operatorname{Ag}(\mathbf{L})\left(\mathrm{H}_{2} \mathrm{O}\right)\right]\right.$ $\left.\left(\mathrm{NO}_{3}\right)\right\}_{n}$ [symmetry codes: i) $\left.0.5-x,-0.5+y, z\right]$. Hydrogen atoms, non-coordinating water molecules and disordered fluorine atoms in (a) are omitted.
Thus, the geometry of Ag atom is three-coordinate with T-shape [N1-Ag1-N3 173.87(11) ${ }^{\circ}, \mathrm{N} 1-\mathrm{Ag} 1-\mathrm{O} 1$ 96.01(11) ${ }^{\mathrm{o}}$, N3-Ag1-O1 $\left.89.78(11)^{\circ}\right]$. In addition, $\mathrm{Ag}(\mathrm{I})$ center interacts with carbon atoms of the central phenyl ring to give two cation $\cdots \pi$ interactions. The distances between the $\operatorname{Ag}(\mathrm{I})$ atom and the central phenyl carbon atoms C10 and C20 are 2.817(4) $\AA$ and 2.880(4) $\AA$, which are slightly longer than the reported $\mathrm{Ag} \cdots \mathrm{C}$ bond length (ca. $2.58 \AA) .{ }^{11}$

In the crystal structure of $\mathbf{1}, \mathbf{L}$ adopts $\mathrm{S}$-shape conformation because there is a crystallographically imposed center of inversion symmetry at the center of central phenyl ring and three component of ligand $\mathbf{L}$ consisting of two azaindolyl groups and one central phenyl group are twisted from each other with dihedral angles of $49.3(1)^{\circ}$ and $50.7(1)^{\circ}$ to minimize steric hindrance between the $\mathrm{Ag}(\mathrm{I})$ center and the central phenyl group of $\mathbf{L}$. These S-shape and twisted dihedral angels of $\mathbf{L}$ lead to give an unusual helix-like zigzag 1-D polymer. In the crystal packing structure, there are the intermolecular $\pi$ - $\pi$ interactions through the face-to-face type stackings between the azaindolyl groups of neighboring 1-D chains with centroid-to-centroid distance of $3.48 \AA$ (see dashed lines in Figure 2a). Additionally, two water molecules and trifluoroacetate interact with each other by hydrogen bonds. The range of the hydrogen bond distances are from 2.763(5) to 2.962(5) $\AA$ (Table 3). These intermolecular interactions contribute to the stabilization of the packing.

For coordination polymer $\mathbf{2}$ consisted of one Ag atom, one $\mathbf{L}$, one water molecule and one nitrate anion, as shown in Figure 1b, the overall structure is basically similar to that of $\mathbf{1}$ except the coordination of water molecule instead of trifluoroacetate. $\mathbf{L}$ with non-coplanar S-shape, in which dihedral angles between 


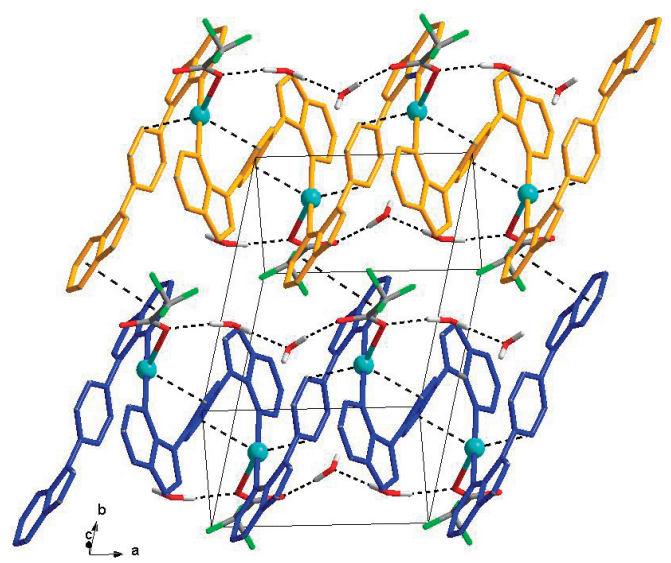

Figure 2. Packing structure of $\mathbf{1},\left\{\left[\mathrm{Ag}(\mathbf{L})\left(\mathrm{CF}_{3} \mathrm{CO}_{2}\right)\right]\left(\mathrm{H}_{2} \mathrm{O}\right)_{2}\right\}_{n}$. The hydrogen bonds, $\mathrm{Ag} \cdots \pi$ and $\pi \cdots \pi$ interactions are represented by dotted lines. Hydrogen atoms of ligands and disordered fluorine atoms are omitted.

Table 3. Hydrogen bonds for $\mathbf{1}$ and $\mathbf{2}$

\begin{tabular}{|c|c|c|c|c|}
\hline $\mathrm{D}-\mathrm{H} \cdots \mathrm{A}$ & $\mathrm{d}(\mathrm{D}-\mathrm{H})$ & $\mathrm{d}(\mathrm{H} \cdots \mathrm{A})$ & $d(D \cdots A)$ & $<$ (DHA \\
\hline \multicolumn{5}{|l|}{ Complex 1} \\
\hline O1W-H1WA $\cdots \mathrm{O} 2$ & 0.87 & 1.90 & $2.763(5)$ & 168.8 \\
\hline $\mathrm{O} 1 \mathrm{~W}-\mathrm{H} 1 \mathrm{WB} \cdots \mathrm{O} 2^{\mathrm{i}}$ & 0.97 & 2.00 & $2.962(5)$ & 171.4 \\
\hline $\mathrm{O} 2 \mathrm{~W}-\mathrm{H} 2 \mathrm{WA} \cdots \mathrm{O} 1 \mathrm{~W}^{\mathrm{ii}}$ & 0.99 & 1.90 & $2.856(5)$ & 162.9 \\
\hline $\mathrm{O} 2 \mathrm{~W}-\mathrm{H} 2 \mathrm{WB} \cdots \mathrm{O} 1$ & 1.02 & 1.95 & $2.930(5)$ & 161.9 \\
\hline
\end{tabular}

Symmetry codes: (i) $-x+1,-y,-z+1$, (ii) $x+1, y, z$

Complex 2

$\begin{array}{lllll}\text { O1W-H1WA } \cdots \mathrm{O}{ }^{\mathrm{i}} & 0.80 & 2.09 & 2.875(6) & 166.8 \\ \text { O1W-H1WB } \cdots 3^{\text {ii }} & 0.80 & 2.23 & 3.009(6) & 163.7\end{array}$

Symmetry codes: (i) $-x+3 / 2, y-1 / 2, z$, (ii) $x, y-1, \mathrm{z}$

the azaindolyl groups and the central phenyl groups are $44.7(1)^{\circ}$ and $52.0(1)^{\circ}$, connects two $\mathrm{Ag}(\mathrm{I})$ atoms through azaindolyl $\mathrm{N}$ atoms to give an unusual helix-like zigzag 1-D polymer consisted of alternate $\operatorname{Ag}(\mathrm{I})$ and $\mathbf{L}$. Ag-N bond lengths are in the range of 2.243(4) - 2.268(4) $\AA$ and one water molecule binds to the $\mathrm{Ag}(\mathrm{I})$ atom (Ag1-O1W 2.692(4) $\AA$ ). Considering the bond angles around $\operatorname{Ag}(\mathrm{I})$ atom (Table 2), the geometry of $\mathrm{Ag}(\mathrm{I})$ center is T-shape. Nitrate anion weakly interact with $\mathrm{Ag}(\mathrm{I})$ atom in the distance of 2.755(4) $\AA$. There are also two cation $\cdots \pi$ interactions with $\mathrm{Ag}(\mathrm{I})$ involving carbon atoms $(\mathrm{Ag} 1 \cdots \mathrm{C} 9=$ $\left.2.877(4) \AA, A g 1 \cdots \mathrm{C} 12^{\mathrm{i}}=2.834(4) \AA\right)$ of the central phenyl rings (Figure $1 b$ ). In packing structure of 2 , the intermolecular $\pi-\pi$ interactions between neighboring 1-D polymeric chains through azaindolyl groups also exist as shown in Figure $2 \mathrm{~b}$. The distance of centroid-to-centroid distance is $3.37 \AA$. In addition, the coordinated water molecule and nitrate anion form the hydrogen bonds in the range of 2.875(6)-3.009(6) $\AA$ to stabilize the packing structure (Table 3).

When irradiated by UV light, the ligand, 1,4-bis(7-azaindoly) benzene, emits a bright blue emission in both the solution and solid states. The emission maximum of the ligand in a $\mathrm{CH}_{2} \mathrm{Cl}_{2}$ solution is at $428 \mathrm{~nm}$ when the concentration of the solution is approximately $10^{-4} \mathrm{M}$, meanwhile a significant red shift is ob-

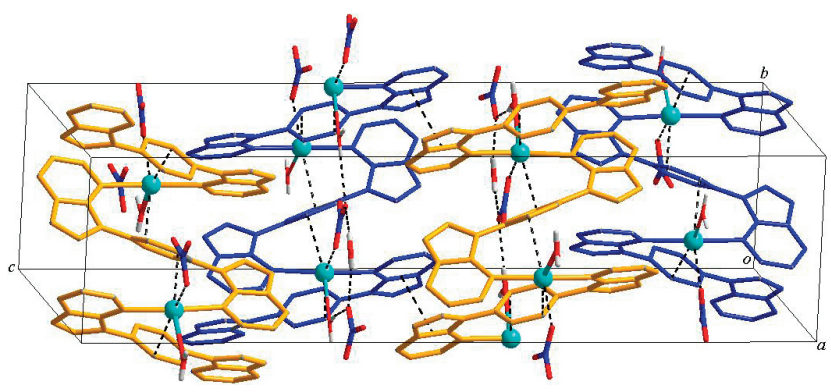

Figure 3. Packing structure of $\mathbf{2},\left\{\left[\mathrm{Ag}(\mathbf{L})\left(\mathrm{H}_{2} \mathrm{O}\right)\right]\left(\mathrm{NO}_{3}\right)\right\}_{n}$. The hydrogen bonds, $\mathrm{Ag} \cdots \pi, \mathrm{Ag} \cdots$ anion and $\pi \cdots \pi$ interactions are represented by dotted lines. Hydrogen atoms of ligands are omitted.

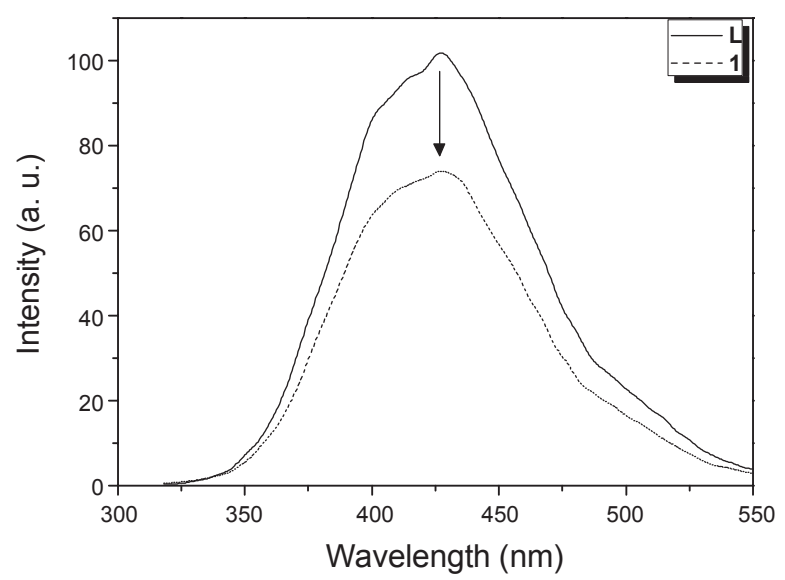

Figure 4. Emission spectra of free ligand (solid line) and $\mathbf{1}$ (dashed line) in $\mathrm{CH}_{3} \mathrm{CN}$.

served (e.g. 0.10 M solution, emission maximum at approximately $450 \mathrm{~nm}$ ) at high concentrations, which is attributed to intermolecular interactions or excimer emission. Compound 1 and $\mathbf{2}$ showed similar emission patterns in solution and solid states. The emission spectra of the ligand, and $\mathbf{1}$ are shown in Figure 4. The emission maximum of $1(428 \mathrm{~nm})$ in a $\mathrm{CH}_{3} \mathrm{CN}$ solution (approx. $10^{-4} \mathrm{M}$ ) is essentially the same as that of the free ligand, 1,4-bis(7-azaindoly)benzene. The emission bands of $\mathbf{1}$ and $\mathbf{2}$ in solution at the same concentration resemble that of the free ligand in solution, indicating that they are all ligandbased emissions. However, the intensity of the emission bands of $\mathbf{1}$ and $\mathbf{2}$ is slightly weaker than that of the free ligand under the same conditions, indicating that the $\operatorname{Ag}(\mathrm{I})$ ion partially quench the emission from the ligand. Furthermore, the emission intensity of 1 is about $70 \%$ of the intensity of the free ligand. These observations support that the ligand has the potential as a fluorescent sensor for $\mathrm{Ag}^{+}$. The selectivity of this ligand as a fluorescent sensor toward various metal ions is being investigated.

\section{Experimental Section}

General consideration. All reagents were purchased from either Aldrich or Strem and without further purification unless otherwise noted. All solvent were freshly distilled from appropriate drying agents prior to use. Conventional schlenk tech- 
niques were used, and reactions were carried out under dry nitrogen atmosphere. ${ }^{1} \mathrm{H}-\mathrm{NMR}$ Spectra were recorded with a Bruker advance $300 \mathrm{MHz}$ or $400 \mathrm{MHz}$ spectrometer instrument. The photoluminescence spectra were recorded on a Perkin LS fluorescence spectrometer.

Preparation of 1,4-bis(7-azaindolyl)benzene (L). 1,4-Dibromobenzene (1.00 g, $4.23 \mathrm{mmol})$, 7-azaindole (1 g, 8.46 $\mathrm{mmol})$, potassium carbonate $(1.17 \mathrm{~g}, 8.46 \mathrm{mmol})$, and cupric sulfate hydrate $(0.05 \mathrm{~g}, 0.21 \mathrm{mmol})$ were mixed in a flask and heated at $210-220^{\circ} \mathrm{C}$ for $6 \mathrm{~h}$. After it was cooled to room temperature, the mixture was dissolved in $\mathrm{CH}_{2} \mathrm{Cl}_{2}(200 \mathrm{~mL})$ and washed with $\mathrm{H}_{2} \mathrm{O}$. The organic layer was dried over $\mathrm{MgSO}_{4}$, and all volatiles were removed under reduced pressure. The residue was purified by column chromatography using ethyl acetate/hexane (1:3) as eluent. The product was recrystallized from ethyl acetate/hexane in $20 \%$ yield. ${ }^{1} \mathrm{H}-\mathrm{NMR}\left(\mathrm{CDCl}_{3}, 300\right.$ $\left.\mathrm{MHz}, 25^{\circ} \mathrm{C}\right) \delta 8.33(\mathrm{dd}, J=4.7,1.6 \mathrm{~Hz}, 2 \mathrm{H}, 7$-azain), 7.94 (dd, $J=7.9,1.6 \mathrm{~Hz}, 2 \mathrm{H}, 7$-azain), 7.86 (s, 4H, Ph), 7.49 (d, $J=$ $3.6 \mathrm{~Hz}, 2 \mathrm{H}, 7$-azain), 7.12-7.08 (m, 2H, 7-azain), 6.61 (d, $J=3.7$ $\mathrm{Hz}, 2 \mathrm{H}, 7$-azain). ${ }^{13} \mathrm{C}$-NMR $\left(\mathrm{CDCl}_{3}, 100 \mathrm{MHz}, 25^{\circ} \mathrm{C}\right) \delta 160.2$, $159.8,143.5,132.6,129.8,129.5,129.0,122.0,118.2,103.2$. $\mathrm{MS}(\mathrm{EI})=310\left[\mathrm{M}^{+}\right]$. Anal. Calcd for $\mathrm{C}_{20} \mathrm{H}_{14} \mathrm{~N}_{4}$ : C, 77.40; $\mathrm{H}$, 4.55; N, 18.05. Found: C, 77.22; H, 4.49; N, 18.12.

Preparation of [1,4-bis(7-azaindolyl)phenyl] silvertrifluoroacetate (1). To a stirred THF $(10 \mathrm{~mL})$ solution of $\mathrm{CF}_{3} \mathrm{COOAg}$ (0.93 g, $4.23 \mathrm{mmol}$ ) was added $\mathbf{L}(1.31 \mathrm{~g}, 4.23 \mathrm{mmol})$ dissolved in THF $(10 \mathrm{~mL})$. A colorless precipitate was formed, and the crude product was separated by filtration. Recrystallization from acetonitrile/ether gave pure 1 in $65 \%$ yield. ${ }^{1} \mathrm{H}-\mathrm{NMR}\left(\mathrm{CDCl}_{3}\right.$, $\left.300 \mathrm{MHz}, 25^{\circ} \mathrm{C}\right) \delta 8.32$ (dd, $J=5.0,1.4 \mathrm{~Hz}, 2 \mathrm{H}, 7$-azain), 8.07 (dd, $J=7.9,1.5 \mathrm{~Hz}, 2 \mathrm{H}, 7$-azain), 7.77 (s, 4H, $P h), 7.42$ (d, $J=$ 3.7 Hz, 2H, 7-azain), 7.23-7.20 (m, 2H, 7-azain), 6.68 (d, $J=3.7$ $\mathrm{Hz}, 2 \mathrm{H}, 7$-azain); ${ }^{13} \mathrm{C}$-NMR $\left(\mathrm{CDCl}_{3}, 100 \mathrm{MHz}, 25^{\circ} \mathrm{C}\right) \delta 160.2$, 159.8, 143.5, 143.2, 133.7, 130.0, 127.9, 124.9, 121.5, 115.5, 115.0, 100.8. HRMS-EI $(\mathrm{m} / \mathrm{z}):\left[\mathrm{MH}^{+}\right]$calcd. for $\mathrm{C}_{22} \mathrm{H}_{14} \mathrm{~N}_{4} \mathrm{~F}_{3} \mathrm{O}_{2}$, 532.2356; found, 532.2334 .

Preparation of [1,4-bis(7-azaindolyl)phenyl] silvertrifluoroacetate (2). Compound 2 was prepared using the same procedure as that described for $\mathbf{1}$. Pure $\mathbf{2}$ was isolated by recrystallization from $\mathrm{CH}_{3} \mathrm{CN} / \mathrm{Et}_{2} \mathrm{O}$ in $79 \%$ yield. ${ }^{1} \mathrm{H}-\mathrm{NMR}\left(\mathrm{CDCl}_{3}, 300 \mathrm{MHz}\right.$, $\left.25{ }^{\circ} \mathrm{C}\right) \delta 11.1(\mathrm{dd}, J=3.7,1.5 \mathrm{~Hz}, 2 \mathrm{H}, 7$-azain), 10.5 (dd, $J=$ 7.9, $1.5 \mathrm{~Hz}, 2 \mathrm{H}, 7$-azain), 10.4 (s, 4H, Ph), 9.98 (d, $J=3.7 \mathrm{~Hz}$, 2H, 7-azain), 9.40-9.35 (m, 2H, 7-azain), 8.80 (d, $J=3.5 \mathrm{~Hz}$, $2 \mathrm{H}, 7$-azain). HRMS-EI $(\mathrm{m} / \mathrm{z}):\left[\mathrm{MH}^{+}\right]$calcd. for $\mathrm{C}_{20} \mathrm{H}_{14} \mathrm{~N}_{5} \mathrm{O}_{3}$, 480.2251; found, 480.2238. We could not obtain ${ }^{13} \mathrm{C}-\mathrm{NMR}$ data of $\mathbf{2}$ due to very low solubility in common solvent.

X-ray crystallography. Single crystal diffraction data of $\mathbf{2}$ were collected on a Bruker Smart diffractometer equipped with a graphite monochromated $\operatorname{Mo~} \mathrm{K} \alpha(\lambda=0.71073 \AA)$ radiation source and a CCD detector (Central Laboratory in GNU). Crystals were isolated from mother liquor and immediately immersed in paratone oil and then mounted. The 45 frames of two dimensional diffraction images were collected at $173 \mathrm{~K}$ and processed to obtain the cell parameters and orientation matrix. A total of 1271 frames of two-dimensional diffraction images were collected, each of which was measured for $5 \mathrm{sec}$. Decay was monitored by 50 standard data frames measured at the beginning and end of data collection. The crystal showed no sig- nificant decay. The frame data were processed to give structure factors using the SAINT-plus. ${ }^{12}$ The structure was solved by direct methods and refined by full matrix least squares methods on $F^{2}$ for all data using SHELXTL software. ${ }^{13}$ For $\mathbf{1}$, two fluorine atoms of trifluoroacetate are disordered over two sites with occupancies of 0.47 or 0.53 obtained the refinement of the site occupancy factors. The non-hydrogen atoms were refined anisotropically. The hydrogen atoms were placed in calculated positions and refined with a riding model with the exception of the hydrogens of solvent water molecules, which were located in difference electron density maps and refined with a riding model. Crystallographic data and structural refinement data for $\mathbf{1}$ and $\mathbf{2}$ are summarized in Table 1.

Acknowledgments. This research was supported by Basic Science Research Program through the National Research Foundation of Korea (NRF) funded by the Ministry of Education, Science and Technology (2009-0072468).

Supplementary Material. Supplementary crystallographic data associated to L, complex $\mathbf{1}$ and $\mathbf{2}$ have been deposited at the Cambridge Crystallographic Data Centre, CCDC No. 783747 and 783748, respectively. Copies of the data can be obtained free of charge on application to CCDC, 12 Union road, Cambridge CB2 1EZ, UK (fax: +44 1223 336033; e-mail: deposit@ ccdc.cam.ac.uk), or electronically viawww.ccdc.cam.ac.uk/ perl/catreq.cgi.

\section{References}

1. Courcot, B.; Tran, D. N.; Fraisse, B.; Bonhomme, F.; Marsura, A.; Ghermani, N. E. Chem. Eur. J. 2007, 13, 3414.

2. (a) Wang, S. Coord. Chem. Rev. 2001, 215, 79 and references therein. (b) Wu, Q.; Lavigne, J. A.; Tao, Y.; D’Iorio, M.; Wang, S. Chem. Mater. 2001, 13, 71 .

3. Song, D.; Wang, S. Eur. J. Inorg. Chem. 2003, 20, 3774.

4. Song, D.; Wu, Q.; Hook, A.; Kozin, I.; Wang, S. Organometallics 2001, 20, 4683

5. Song, D.; Wang, S. Comments Inorg. Chem. 2004, 25, 1.

6. Kang, Y.; Lee, J.; Song, D.; Wang, S. Dalton Trans. 2003, 18, 3493.

7. (a) Kim, D.-H.; Hong, C.-K.; Lee, P. H.; Kang, Y. Bull. Korean Chem. Soc. 2008, 29, 2270. (b) Jung, S. O.; Zhao, Q.; Park, J.-W.; Kim, S. O.; Kim, Y.-H.; Oh, H.-Y.; Kim, J.; Kwon, S.-K.; Kang, Y. Org. Electron. 2009, 10, 1066. (c) Lee, S. J.; Park, K.-M.; Yang, K.; Kang, Y. Inorg. Chem. 2009, 48, 1030. (d) Ko, S.; Choi, H.; Kang, M.-S.; Hwang, H.; Ji, H.; Kim, J.; Ko, J.; Kang, Y. J. Mater. Chem. 2010, 20, 2391. (e) Ji, H.; Kim, J.; Yoo, J. W.; Lee, H. S.; Park, K.-M.; Kang, Y. Bull. Korean Chem. Soc. 2010, 31, 1371. (f) Jung, H.; Hwang, H.; Park, K-M.; Kim, J.; Kim, D.-H.; Kang, Y. Organometallics 2010, 29, 2715.

8. Kang, Y.; Lee, S. S.; Park, K.-M.; Lee, S. H.; Kang, S. O.; Ko, J. Inorg. Chem. 2001, 40, 7027.

9. Kang, Y.; Seward, C.; Song, D.; Wang, S. Inorg. Chem. 2003, 42, 2789.

10. (a) Goodbrand, H. B.; Hu, N. X. J. Org. Chem. 1999, 64, 670. (b) Lindley, J. Tetrahedron 1984, 40, 1433. (c) Fanta, P. E. Synthesis 1974, 1

11. Gano, J. E.; Subramaniam, G.; Birnbaum, R. J. Org. Chem. 1990, 55,4760 .

12. Bruker, SMART (ver. 5.625) and SAINT-plus (ver. 6.22): Area Detector Control and Integration Software; Bruker AXS Inc.: Madison, Wisconsin, 2000.

13. Bruker, SHELXTL (ver. 6.10): Program for Solution and Refinement of Crystal Structures; Bruker AXS Inc.: Madison, Wisconsin, 2000. 